OPEN ACCESS

Edited by:

Anita Drumond

University of Vigo, Spain

Reviewed by:

Fabio D'Andrea,

Laboratoire de Meteorologie

Dynamique/Institut Pierre Simon

Laplace, France

Janini Pereira,

Federal University of Bahia, Brazi

*Correspondence:

Verónica Torralba,

Climate Forecasting Unit, Institut

Català de Ciències del Clima, Doctor

Trueta, 203, 08005 Barcelona, Spain

veronica.torralba@ic3.cat

Specialty section:

This article was submitted to Atmospheric Science,

a section of the journal

Frontiers in Earth Science

Received: 03 March 2015 Accepted: 08 September 2015

Published: 24 September 2015

Citation:

Torralba V, Rodríguez-Fonseca B, Mohino E and Losada T (2015) The non-stationary influence of the Atlantic

and Pacific Niños on North Eastern

South American rainfall.

Front. Earth Sci. 3:55

doi: 10.3389/feart.2015.00055

\section{The non-stationary influence of the Atlantic and Pacific Niños on North Eastern South American rainfall}

\author{
Verónica Torralba ${ }^{1 *}$, Belén Rodríguez-Fonseca ${ }^{2,3}$, Elsa Mohino ${ }^{2}$ and Teresa Losada ${ }^{2}$ \\ ${ }^{1}$ Climate Forecasting Unit, Institut Català de Ciències del Clima, Barcelona, Spain, ${ }^{2}$ Departamento de. Física de la Tierra, \\ Facultad Ciencias Físicas, Astronomía y Astrofísica I, Universidad Complutense de Madrid, Madrid, Spain, ${ }^{3}$ Facultad \\ Ciencias Físicas, Instituto de Geociencias (Consejo Superior de Investigaciones Cientificas - Universidad Complutense de \\ Madrid), Madrid, Spain
}

Rainfall variability over the tropical Atlantic region is dominated by changes in the surface temperature of the surrounding oceans. In particular, the oceanic forcing over Northeast of South America is dominated by the Atlantic interhemispheric temperature gradient, which leads its predictability. Nevertheless, in recent decades, the SST influence on rainfall variability in some tropical Atlantic regions has been found to be non-stationary, with important changes of the Atlantic and Pacific influence on Sahelian rainfall which appear to be modulated at multidecadal timescales. In this work, we revisit the SST influence over Northeast of South America including the analysis of the stationarity of this relationship at interannual timescales. Principal Component Analysis has been applied to the interannual component of rainfall during the March-April-May season. Results show how the SST forcing on the first mode of rainfall variability, which is a dipole-like pattern generated by the changes in the seasonal migration of the Intertropical Convergence Zone, is different depending of the considered period. The response to the SST anomalies in the Pacific basin is opposite to the Atlantic one and affects different areas. The Atlantic Niño influences rainfall variability at the beginning of the XX century and after 1970, while the Pacific Niño plays a major role in the variability of the rainfall in the Northeast of South America from 1970 onwards. The combined effect of both basins after the 1970s amplifies the anomalous rainfall response.

\footnotetext{
Keywords: multidecadal modulations, Northeastern South America rainfall, interannual variability, SST forced response, atmosphere general circulation models
}

\section{Introduction}

The northern South America is a complex region, because it is a large territory where different weather systems act. This region includes the Amazon region with one of the most intense convective activity areas in the world (Andreoli et al., 2012) and also the northeast of Brazil which is characterized by frequent and intense droughts due to its semiarid climate (Nobre and Shukla, 1996; Rao et al., 2006). The interaction between different atmospheric phenomena that appear in the whole region and local surface conditions (like topography, vegetation, and land use), generates a non-homogenous rainfall distribution that varies in a wide temporal and spatial range (Espinoza Villar et al., 2009; Sierra et al., 2015). 
The present work focuses on the Northeast of South America (NESA) defined hereafter as the region between the $15 \mathrm{~N}-$ $15 \mathrm{~S}$ and $30-75 \mathrm{~W}$. The annual cycle of precipitation in that region is led by changes in the position of the Intertropical Convergence Zone (ITCZ), which suffers meridional shifts following the seasonal movement of insolation, producing bimodal or unimodal precipitation patterns over specific regions of South America and causing non-periodic events of droughts or floods in NESA region (Sperber and Palmer, 1996; Uvo et al., 1998; Poveda et al., 2006). The annual cycle of precipitation over NESA is not completely explained by the ITCZ excursions, the existence of regional processes strongly influences the amounts of precipitation over the region, defining local rainfall patterns (Sierra et al., 2015). The position of the ITCZ also plays an important role in the connection of the rainfall variations over the Northeast of South America with rainfall anomalies in the Sahel region (Rao et al., 2006). When the ITCZ is displaced to the south (north), higher than normal rainfall occurs over the Northeast of South America (Sahel).

The ocean is the main driver of interannual to decadal changes in rainfall in the NESA. At interannual timescales, anomalous rainfall is driven by changes in the tropical Atlantic sea surface temperatures (SST) and the remote influence of the tropical Pacific anomalous SSTs (Giannini et al., 2004; Grimm and Tedeschi, 2009). Rodrigues et al. (2011) have found how the tropical Pacific exerts influence over the tropical Atlantic in a way that El Niño has a positive effect on Atlantic Niños. Precipitation variability is thus driven by the two leading modes of variability of SST in the tropical belt: the Atlantic Niño (Zebiak, 1993) and the Pacific Niño (Philander, 1990). Although the separated influence of the tropical Atlantic and Pacific oceans on NESA has been documented, to our knowledge there is no work tackling on the stationarity of their relationship with NESA rainfall. Moreover, recent studies have found how the Atlantic and Pacific Niños appear anticorrelated in summer during the decades after the 1970s and at the beginning of the XX century (Polo et al., 2008, 2015; Rodríguez-Fonseca et al., 2009; Martín-Rey et al., 2012, 2014). The concomitant action of both basins on the NESA rainfall region has not been yet explored, although important impacts have been found for the Sahel (Losada et al., 2012; Rodríguez-Fonseca et al., 2015). Such studies have highlighted that the SST influence over West African region is not stationary. In this way, before the 1970s, the Pacific El Niño has a different impact over Sahelian rainfall than after that period. These works have demonstrated that this variability is due to the non-linear relationship between the precipitation in that region and the SST in the tropical Atlantic.

All these findings have encouraged us to explore the stationarity of the SST influence on the interannual variability of rainfall in some regions of the North of South America. The present study analyses the non-stationarity in the interannual variations of rainfall in NESA, as well as the associated influence of the Atlantic and Pacific tropical basins when they act together in opposite phases (Altantic El Niño and Pacific La Niña) as was observed after the 1970s.

The first part of this work presents an observational analysis which includes an assessment of the stationarity of precipitation anomalies and their relation with SST variability in the tropics. In the second part, we study the response obtained using sensitivity experiments that consider the concomitant influence of the Atlantic and Pacific main modes of interannual variability on the region.

This paper is divided as follows. Section Materials and Methods describes the used datasets and the methodology used. The results are shown in section Results and discussed in section Discussion and Conclusions.

\section{Materials and Methods}

\section{Datasets \\ Precipitation}

To undertake robust analyses, three high resolution land surface precipitation datasets are used. They are based on station data using different methods of spatial interpolation from the raingauge station locations to the nodes of the $0.5^{\circ}$ grid. The interpolations are carried out with different versions of the Shepard's algorithm (Shepard, 1968; Willmott et al., 1985). The datasets are: Climate Research Unit version 3.1 (CRU TS 3.1, Harris et al., 2013; from 1901 to 2009), University of Delaware (UDel, Matsuura and Willmott, 2009, from 1900 to 2008); and Global Precipitation Climatology Center (GPCC, Schneider et al., 2008, from 1901 to 2007). These three data bases only have information over land which is a handicap for continuity studies of analysis of ITCZ-related variability.

\section{Sea Surface Temperatures and Indices}

Hadley Centre Sea Ice and Sea Surface temperature (HadISST) data is used (Rayner et al., 2003). This dataset provides reconstructed monthly SST and sea ice data on a horizontal grid with a resolution of $1^{\circ} \times 1^{\circ}$ and spans from 1870 to 2011 .

Two indices are calculated from this dataset at interannual scales: the ATL3 and NINO3 indices. The ATL3 index (Zebiak, 1993 ) is defined through the SST anomaly mean in the tropical Atlantic located between $3^{\circ} \mathrm{N}-3^{\circ} \mathrm{S}$ and $20^{\circ} \mathrm{W}-0^{\circ}$. The Niño3 index (Trenberth and Stepaniak, 2001) results from the SST anomalies averaged in the equatorial Pacific region $\left(5^{\circ} \mathrm{S}-5^{\circ} \mathrm{N}\right.$, $\left.150^{\circ} \mathrm{W}-90^{\circ} \mathrm{W}\right)$.

\section{Methods}

\section{Statistical Analysis}

To find out how the rainfall variability is organized in NESA region, Principal Component Analysis (PCA/EOF) has been applied to three different observational datasets. This discriminant analysis statistical technique is very useful to extract modes of variability explaining a high percentage of the field variance (Wilks, 2006). The analysis is applied to define the modes of precipitation variability for each of the three datasets considered. The study focuses on the assessment of the leading mode of variability with the aim of inferring the associated mechanisms involved in the origin of the anomalous rainfall in NESA.

The rainfall variability in the studied region has a strong variability at different timescales. In this paper we focus on interannual timescales. Therefore, in order to remove the decadal 
influence, the anomalous precipitation time series are filtered using a Butterworth filter (order 10, cut-off period of 13 years), which is applied at each grid point before the EOF analysis (Mann, 2008).

The statistical significance shown along this work has been obtained from a Student $t$-test with $\alpha=0.05$.

\section{Atmospheric General Circulation Model Experiments}

AGCM simulations are used in this study to check the concomitant action of the Atlantic and Pacific tropical forcing on the NESA region. These simulations were carried out in Losada et al. (2012) to study the oceanic influence over West Africa. However, given the similarities between the SST variability modes that affect both tropical regions (Rao et al., 2006) and the fact that we want to verify the same hypothesis of the Atlantic and Pacific influence on NESA, we have considered their use in this study. The simulations were performed with the Atmospheric Global Coupled Model (AGCM) UCLA v.7.3 (Mechoso et al., 2000; Richter et al., 2008) with a horizontal resolution of $2.5^{\circ}$ in longitude and $2^{\circ}$ in latitude and a vertical resolution of 29 levels.

Three AGCM experiments have been analyzed. In the first experiment the SST anomalies prescribed are those from whole tropical region (Atlantic and Pacific) and they are added to the climatological SST values for the period 1979-2005, which is considered as the reference period. In these experiments, an Atlantic Niño appears together with a Pacific La Niña. In the second experiment the SST anomalies in the Tropical Atlantic (corresponding to an Atlantic Niño) are retained and they are added to the SST climatology in the Atlantic basin for the reference period. In the third experiment the anomalies in the Tropical Indo-Pacific are considered (Corresponding to a Pacific La Niña) and they are added to the mean SST values, for the reference period in the Indian and Pacific basins.

All the experiments are 14-month long (from February to April), 10-member ensemble integrations, in which the ensembles differ in a slight perturbation of the initial conditions. The control simulation is a 10 -member ensemble integration with climatological, monthly-mean varying SST corresponding to the 1979-2005 period and the difference of the control simulation with the sensitivity experiments has been used to assess the response to the anomalous SST over the rainfall in the NESA region. We have focused our analysis in the rainy season (MAM) of the Northeast of South America.

\section{Results}

\section{Seasonal Cycle and Variability Modes of Precipitation}

The annual cycle of precipitation over tropical South America shows the characteristics of a monsoon system, with distinct wet and dry seasons for many areas (Gan et al., 2004). To explore the latitudinal evolution of rainfall throughout the year in the NESA region, a hövmoller diagram of the rainfall is presented (Figure 1A).

The hövmoller (Figure 1A) shows a maximum of the precipitation from February to April, between $5^{\circ} \mathrm{S}$ and the
Equator. It is followed by a displacement to the north by midApril and a strong reduction of rainfall south of the Equator. These features in the evolution of rainfall determine the rainy season in the region, which corresponds to the boreal spring (MAM, March-April-May). Horizontal maps in the NESA region have been also represented in Figure 1B, including the seasonal means in MAM (March-April-May and in SON (SeptemberOctober-November). It can be seen how rainfall ranges from $18 \mathrm{~mm} /$ day during the boreal spring, to $0 \mathrm{~mm} /$ day during the autumn season. These abrupt changes in rainfall coincide with the meridional movements of the ITCZ, a result that has been highlighted by many authors (Moura and Shukla, 1981; Sperber and Palmer, 1996; Uvo et al., 1998; Giannini et al., 2004), who also deem the ITCZ as the main driver of the rainfall variability in the Northeast of South America.

To evaluate the precipitation variability at interannual timescales, the leading mode of MAM rainfall variability has been determined using Principal Components Analysis (Figure 2). This analysis has been carried out using the three datasets considered in the study which have been filtered using a Butterworth filter. The variance percentages explained by CRU, UDel, and GPCC are 23.8, 24.4, and 24.2\%, respectively.

The spatial pattern of this mode of variability displays the same structure for the three datasets (Figure 2A). It corresponds with a dipole-like pattern, suggesting that the anomalies in the rainfall are linked to the meridional displacements of the ITCZ, which would increase rainfall in one side of the equator and decrease in the other. Therefore, when the ITCZ does not reach its most southern position (close to the northeast) droughts appears in northeast Brazil, but when the ITCZ stays longer in the south, heavy rains occur in the northeast of Brazil. The anomalies in the ITCZ shifts are mainly produced by variations in the SST interhemispheric gradient in the Atlantic (Uvo et al., 1998).

Principal components (PC) time series (Figure 2B) show remarkable changes in amplitude, from a [-1 1$]$ range in the 1950-1970 period to a [-2 2] range in the previous and forthcoming decades. In fact, the variances in both periods have been compared and they display significant changes in amplitude in certain periods which could be due to the existence of external influences, as those given by the ocean, acting changing the amplitude of rainfall variability at those timescales.

In order to clarify the factors modulating these changes in amplitude (non-stationarities), in the next section, a study is done for separate periods including the analysis of the relation to the ocean.

\section{Influence of SST on the Rainfall Interannual Variability}

The regression map obtained from the projection of the PC associated with the first EOF of precipitation from the UDel dataset onto the SST anomalous field (Figure 3A) shows that lower precipitation (higher precipitation) in the northeast of Brazil region is connected with a warming (cooling) at the East of the tropical Pacific, together with positive (negative) anomalies of the SST over the tropical North Atlantic and negative (positive) anomalies over the tropical South Atlantic. The SST anomalies over the tropical Atlantic produce the strengthening (weakening) 

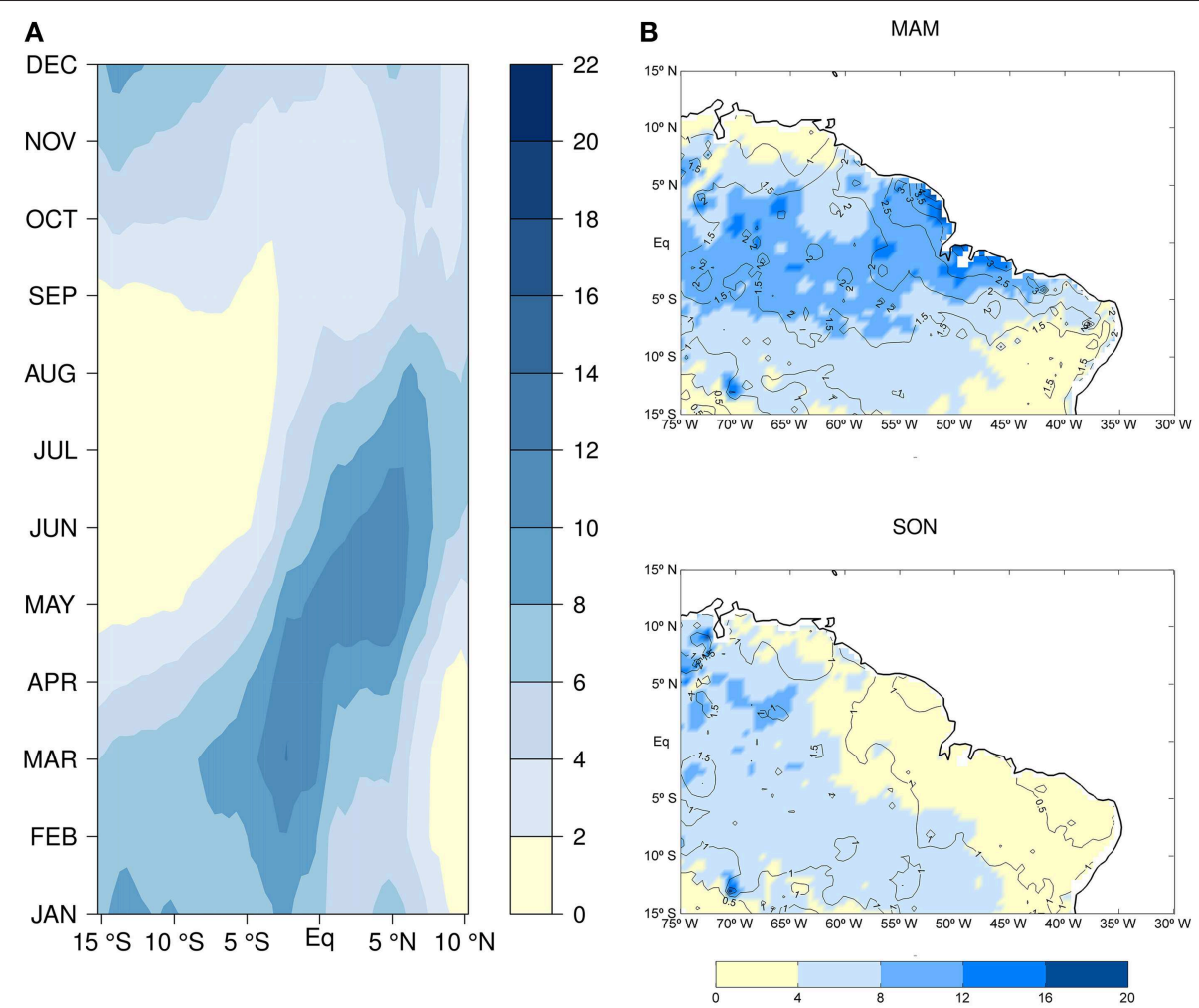

FIGURE 1 | (A) Hövmoller diagram with the evolution in time and latitude of the average precipitation per month in the region of 35-65 W. (B) Seasonal average of rainfall for UDel in the boreal spring months, March-May, (top panel) and autumn months September-November (bottom panel). Units are mm/day. Contours show the standard deviation.

of the SST interhemispheric gradient. This result agrees with those obtained previously by other authors (Harzallah et al., 1996; Chiang et al., 2000; Cazes-Boezio et al., 2003), who affirm that the dipole rainfall pattern over the NESA region is related to variability in the position of the ITCZ, which in turn is produced by SST anomalies.

The SST anomalous patterns related to rainfall variability in the NESA region include the two main modes of variability at interannual timescales in the Pacific and Atlantic basins, the Atlantic and the Pacific Niño, which agrees with those described by Hastenrath (2006) with an influence on the rainfall variability. To analyse the stationarity in the relationship between the rainfall and the Atlantic and Pacific Niño in the NESA, correlations have been computed between the leading $\mathrm{PC}$ of rainfall and the ATL3 and NINO3 indices using a 20 -year sliding window (Figures 3B,C).

An interesting result arises when correlating the PC from UDel dataset with the ATL3 index (Figure 3B). The correlations are only significant in the periods 1905-1920 and 1965-1980 in agreement with changes in the PC amplitude. Similar behavior has been obtained when using CRU and GPCC datasets (not shown). The non-stationary relationship between ATL3 and the PCs seems to be robust and it means that the leading rainfall mode of variability is only modulated by the Atlantic Niño in certain periods (when the correlation is significant).
This result is in agreement with the one obtained by Losada et al. (2012) for the Sahel and López-Parages and RodríguezFonseca (2012) for Europe and demonstrates the importance of evaluating teleconnections with rainfall in a non-stationary way. Also the relationship between the Atlantic and Pacific Niños has been found to be modulated only during some decades, which coincides with those obtained in the present analysis (MartínRey et al., 2014; Polo et al., 2015). This absence of stationarity has been found to be related to changes in the background state of the ocean, for which different dynamical mechanisms operate and produce the emergence of different teleconnections (Martín-Rey et al., 2014).

Regarding the influence of the Pacific El Niño, Figure 3C displays the sliding windows correlations between NINO3 index and rainfall PC obtained with UDel dataset. From the 1970s the correlation between the PC and the NINO3 index is strong and statistically significant, while before the 1970s the correlation is weak and not statistically significant. Similar results were obtained with the other two long datasets (not shown). Hence, the relationship between rainfall in NESA and SST in the Pacific is also non-stationary.

The present results agree with a former study of Chiang et al. (2000), who showed that the Atlantic ITCZ variability is linked to that for the eastern Pacific in a non-stationary way through the Walker circulation as it respond to changes in equatorial Pacific 
A
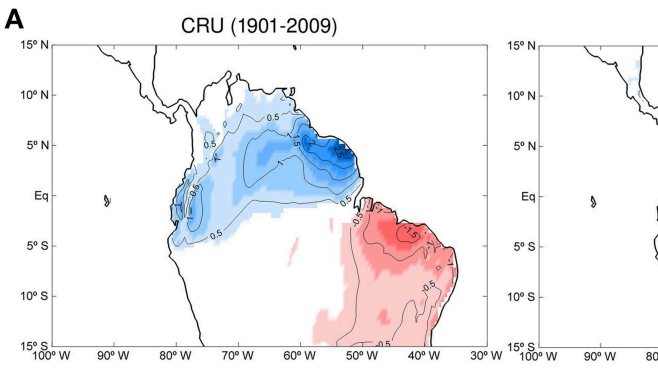

Del (1900-2008)

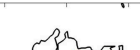

(a)
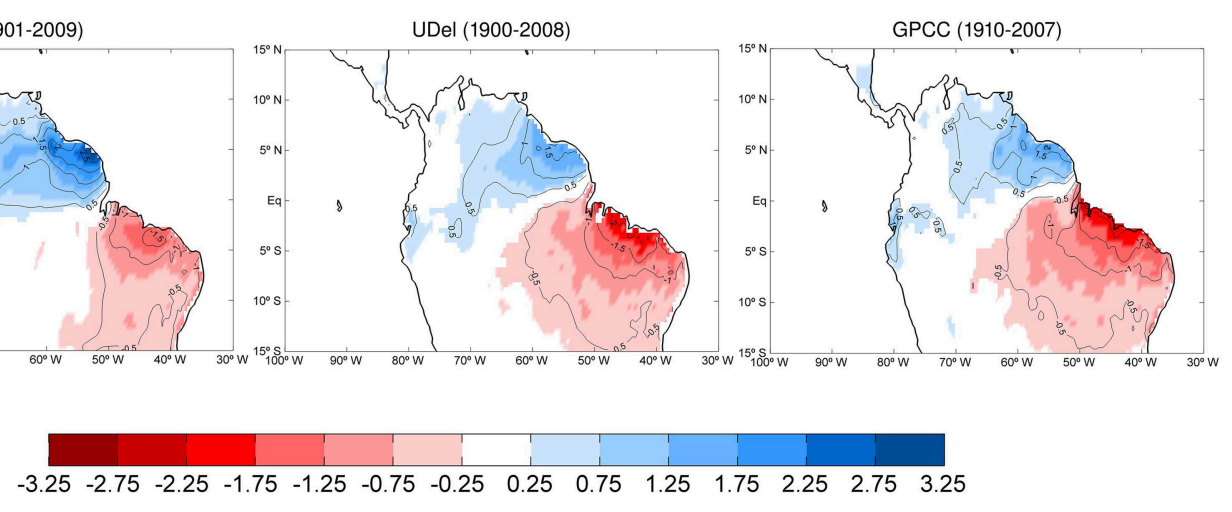

B

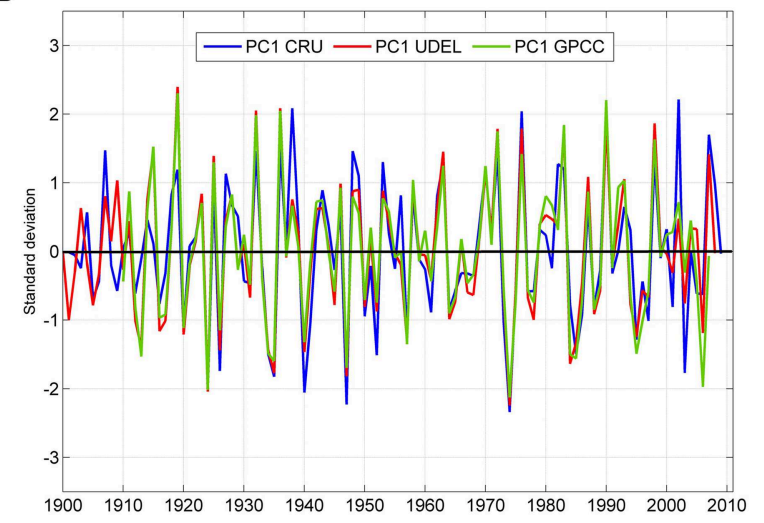

FIGURE 2 | (A) Leading empirical orthogonal function of the March-April-May (mm/day per std in the PC) anomalous rainfall. The regions with correlations significant at the 95\% level are contoured. (B) Standardized principal component (PC1). They are associated with CRU (blue line), UDel (red line), and GPCC (green line) rainfall anomalies in March-April-May.

convection. We speculate that the Atlantic ITCZ variability, that is the main driver of the rainfall over the NESA region, can be modulated by the Atlantic-Pacific Niños connection. In that work the authors present graphical information (not interpreted) of this Atlantic-Pacific connection in relation to their findings, a fact that further encourage the importance of our results.

In summary, although the Atlantic has a significant influence at the beginning of the XX century and after the 1970s, both the Atlantic and Pacific main modes of interannual variability have a significant impact on the PC only after the 1970's, because at the beginning of the XX century the Pacific influence is not significant. Such change of impacts could be related to the late 1970s climate shift reported by Baines and Folland (2007), who argue that in the 1970s decade relevant characteristics of the climate changed. Such changes were particularly relevant over the Tropical regions, changing rainfall over the Amazon basin and northeast Brazil. In addition Chiang et al. (2000) indicated that the influence of the Pacific on the Atlantic as consequence of multidecadal changes in the ITCZ could be due to multidecadal changes in the ocean mean state and this could be responsible of enhancing convection in the western equatorial Atlantic. This multidecadal modulation will be further analyzed in the next section.

\section{Multi-decadal Modulation of Precipitation: Before and After 1970}

To confirm the relationship between the anomalous rainfall and the SST anomalies in the Atlantic and Pacific, the influence of NINO3 and ATL3 has been analyzed for two different periods 1900-1970 and 1970-2008 and rainfall composite analysis has been performed.

The composite maps which shows the relationship between the ATL3 index and the rainfall in the study region (Figure 4A) have been calculated as the difference between the composite map of the UDel rainfall ( $\mathrm{mm}$ /day) for the event ATL3 $>1$ minus the composite map for the event ATL3<-1 in the period before 1970 (left column) and after 1970 (right column).

The composite analysis suggests that before the 1970s, the effect of the positive phase of the Atlantic El Niño on anomalous rainfall on NESA is a dipole-like pattern of rainfall anomalies, with positive anomalies in the northeast of Brazil and negative anomalies in the north of NESA (Figure 4A). This pattern might be related to the significance relationship observed in the Figure 3B during the decades of 1910-1940. These composite maps have been also computed for CRU and GPCC datasets and they show a similar pattern (not shown). After 1970 the pattern is a dipolar structure (Figure 4B) as in the previous period 


\section{A Regression map. PC1 UDel precipitation and SST.}

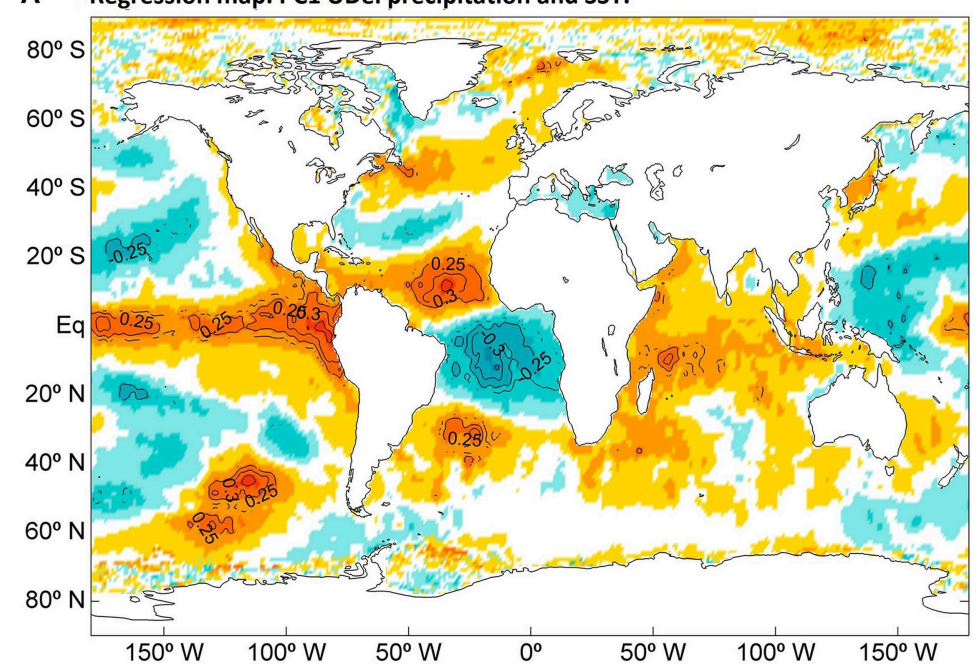

B Sliding windows correlation- 20 years. ATL3 index - PC1 UDel precipitation.

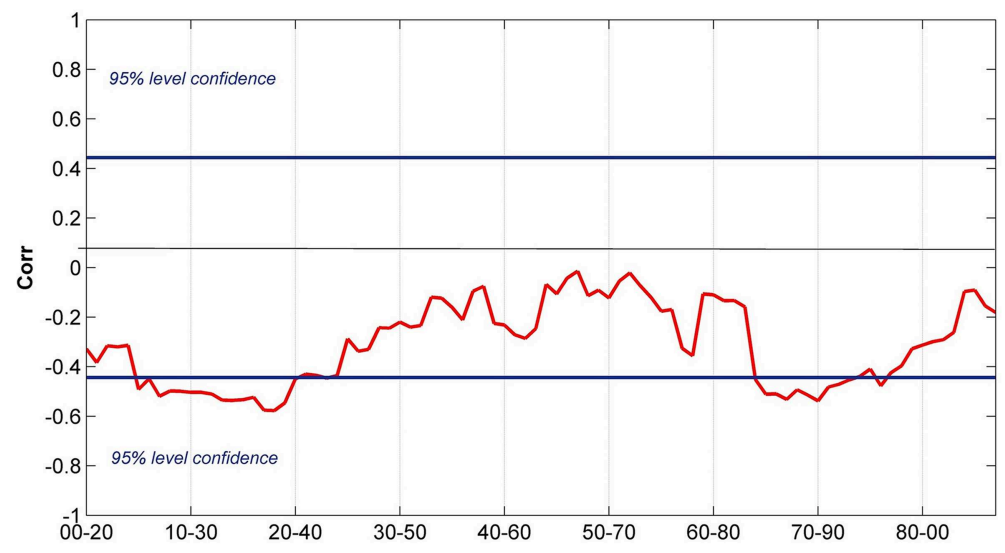

C Sliding windows correlation- 20 years. NINO3 index - PC1 UDel precipitation.

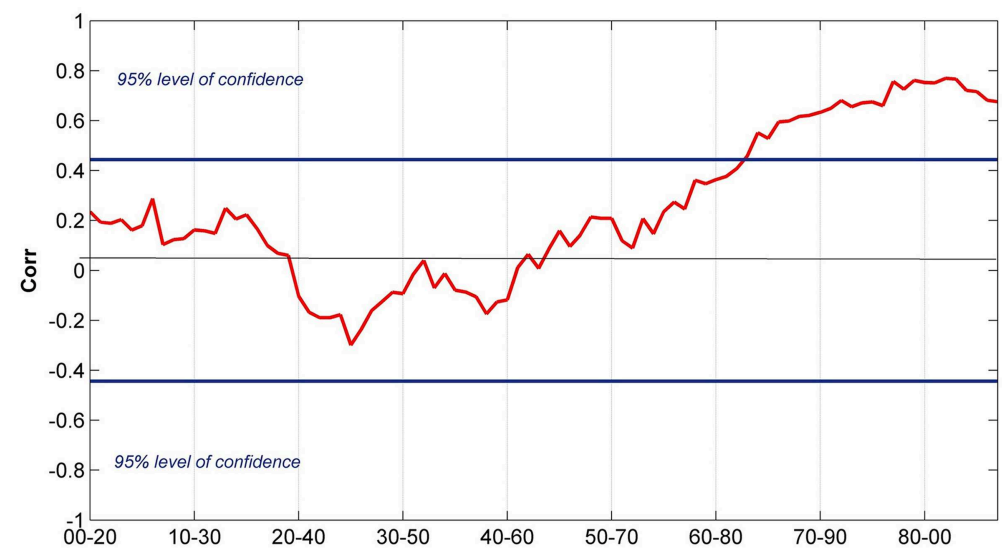

FIGURE 3 | (A) Regression map of anomalous SST onto the PC1 ( ${ }^{\circ} \mathrm{C} / \mathrm{std}$ in the PC) obtained for UDel dataset. The regions with correlations significant at the $95 \%$ level are contoured. (B) Twenty year moving window correlation between the standardized PC1 associated with the leading mode computed UDel and the ATL3 index (red line). In the horizontal axis, the year in which the period of 20 year starts is represented. (C) Twenty year moving window correlation between the standardized PC1 associated with the leading mode computed UDel and the NINO3 index (red line). In the horizontal axis, the year in which the period of 20 year starts is represented. The dark blue lines show the thresholds over which correlations are significant at 95\% confidence level. 
A Composites - ATL3 and UDel rainfall anomalies

1900-1970

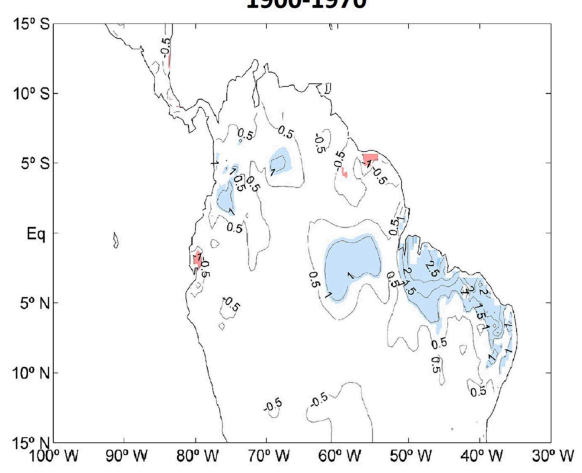

B Composites - NINO3 and UDel rainfall anomalies

1900-1970

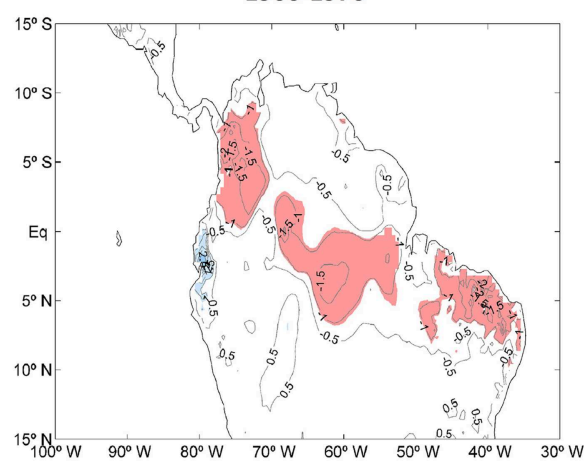

1970-2007

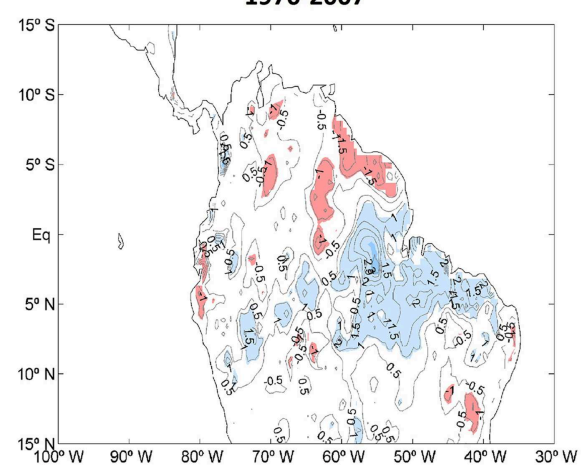

1970-2007

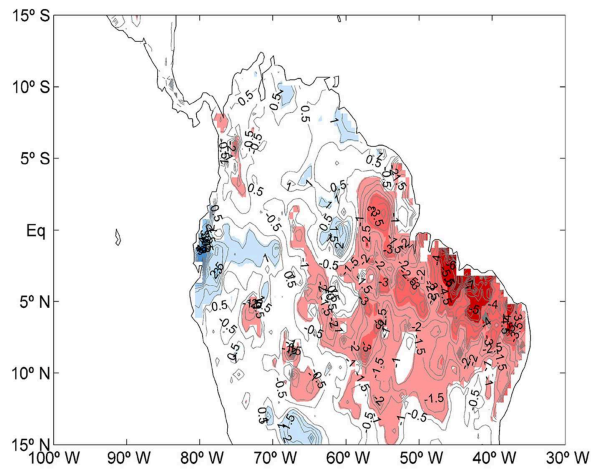

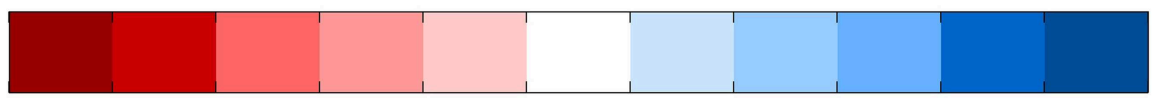

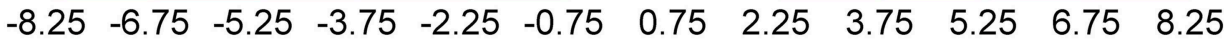

FIGURE 4 | Difference between the composite map of the UDel rainfall ( $\mathbf{m m} /$ day) for the event. (A) ATL3 > 1 minus the composite map for the event ATL3 $<-1$ in the period before 1970 (left column) and after 1970 (right column). (B) NINO3 > 1 minus the composite map for the event NINO3 <-1 in the period before 1970 (left column) and after 1970 (right column). Contoured areas represent the values of the differences, expressed in mm/day, while the regions with correlations significant at the $95 \%$ level are shaded.

(Figure 4A), although the anomalies are slightly weaken, due to the shorter period (1970-1990) in which the observed correlation is significant (Figure 3B). The pattern coincides with the first mode of variability for the high frequency rainfall in NESA region. Some differences exist, however, as those significant anomalies located closer to the coast that could be explained for the higher vicinity of the Atlantic Ocean and, therefore, with a higher influence of this basin over the rainfall.

When an Atlantic Niño occurs, positive SST anomalies appear in the Tropical South Atlantic. These positive anomalies weaken the interhemispheric gradient of the Atlantic SST, and this fact enhances the shift of the ITCZ to the Southern Hemisphere and the appearance of rainfall in the northeast of Brazil region. This anomalous pattern, linked to the ATL3 index, suggests the Atlantic Niño as one of the essential phenomena explaining the interannual variability of the precipitation in the NESA region.

To ensure the robustness of this result, an AGCM simulation in which SST anomalies in the tropical Atlantic (TA experiment) with an Atlantic Niño configuration are prescribed is analyzed (see section Methods for description). Figure 5A presents the rainfall anomalies corresponding to the tropical Atlantic experiment, indicating a significant increase of precipitation in the equatorial rainfall with a decrease in the north of the NESA region, as a response of warm SST anomalies in the equatorial Atlantic.

Regarding the Pacific, the different response of the NESA rainfall to the Pacific El Niño before and after 1970 is examined by calculating the composite maps of anomalies. These maps have been calculated as the difference between the composite for Pacific Niño events minus the composite for Pacific Niña events in two different periods (Figure 4B). These composite maps have been computed based on the years with NINO3 $>1$ (Pacific Niño) and years with NINO3 $<-1$ (Pacific Niña). Before 1970 (Figure 4B, left column) negative anomalies appear in the northwest of South America, but in the northeast of Brazil there are no significant anomalies in the rainfall. This result reveals 


\section{A Atlantic Niño}

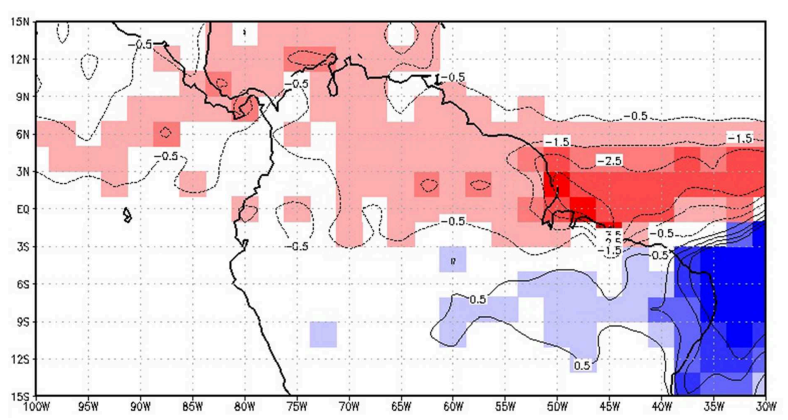

\section{B Pacific Niña}

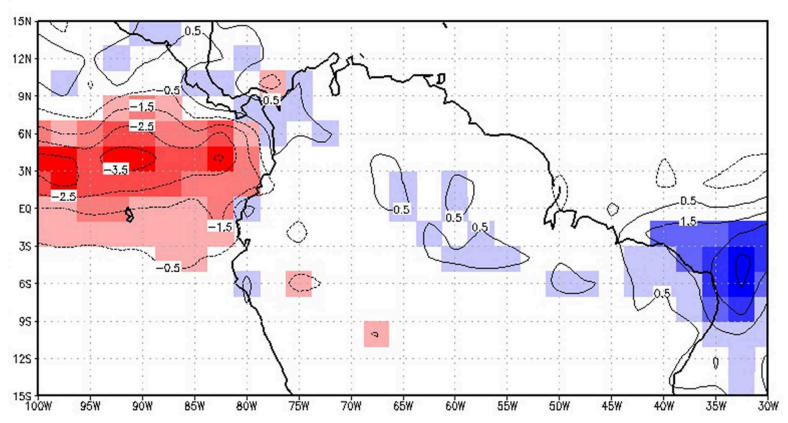

C Atlantic - Pacific

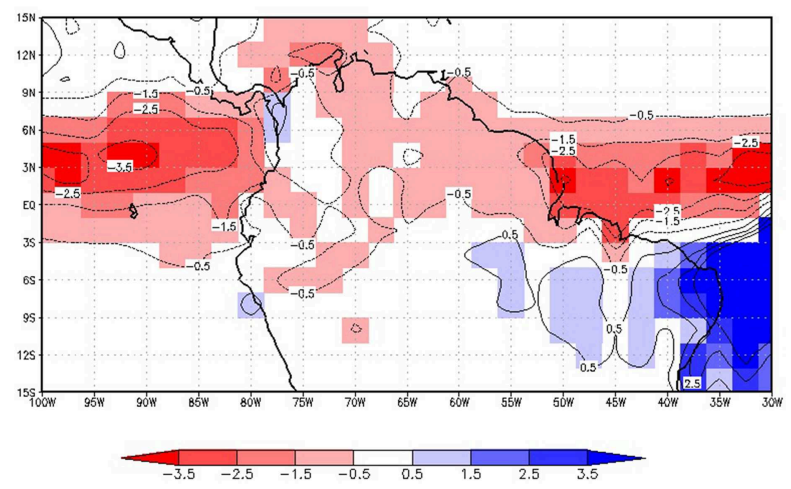

FIGURE 5 | (A) Rainfall anomalies for the Atlantic Niño simulation. (B) Rainfall anomalies for the Pacific Niño simulation. (C) Rainfall anomalies for the simulation in whole Tropical region (Atlantic Pacific). Contoured areas represent the values of the rainfall, expressed in $\mathrm{mm} /$ day, while the regions with correlations significant at the $95 \%$ level are shaded.

that the Pacific Niño events do not project on the interannual leading mode of variability of the rainfall in the NESA region during this period. However, after 1970 the anomalous pattern shows higher similarity with the leading mode of interannual rainfall variability over NESA (Figure 2A), especially over the southern centers of action of the mode. This result confirms the influence of the Pacific Niño in the interannual variability of the precipitation over the whole Amazonian basin during those decades (Rodrigues et al., 2011; Kayano et al., 2013).

To confirm this result, an AGCM sensitivity experiment for the tropical Indo-Pacific region is evaluated (see section Methods for description). Rodríguez-Fonseca et al. (2009) showed that after the 1970s, the Atlantic and Pacific El Niños were highly anticorrelated and Losada et al. (2012) performed AGCM sensitivity experiments to explore the influence of this interbasin connection on Sahelian rainfall. Therefore, to be consistent with the previous AGCM experiment, in which an Atlantic El Niño was simulated, we have chosen to analyse a simulation for the Pacific La Niña. The climatology used in both simulations starts after 1970, when the influence of the Pacific SST is higher (Figure 3C). It can be seen how the response to a cooling in the Pacific is an increase in rainfall over the Atlantic coast of South America, which extends to latitudes south of the Equator (Figure 5B).

If we assume a linear response of rainfall to the SST anomalies [as was found in Losada et al. (2012) for the Sahel], the sum of the Pacific and Atlantic response is a reinforcement of the signal over the northeast of Brazil, as shown in Figures 5A,B. To test such hypothesis, we plot in Figure 5C the rainfall response over NESA given by the simulation in which Atlantic El Niño and Pacific La Niña SST anomalies were used. The combined effect of the two basins produces a dipole-like pattern similar to the leading mode of variability. The positive anomalies in the north of equatorial region in the Atlantic coast of NESA region related to the Atlantic Niño are strengthen by the effect of the Pacific Niña which produce and increase of rainfall in the study region. Thus, contrary to the Sahel in which the concomitant action of both basins cancels the individual signals, over the NESA, the Atlantic-Pacific Niños connection adds their individual effects on rainfall. This novel result is very important for predictability issues and to better assess the SST influence on rainfall in the region.

\section{Discussion and Conclusions}

In this work the interannual rainfall variability in the Northeast of South America has been investigated in relation to the ocean forcing, with special emphasis in the non-stationarities of the found teleconnections. In particular, the different effect of the Pacific and Atlantic along time is explored together with the concomitant action of both basins on NESA rainfall.

The study focuses on the first mode of variability of the rainfall during the March-April-May season, which is characterized by a north-south dipole-like pattern which appears in response to the variability in the ITCZ shifts produced by SST anomalies. We show through observational and AGCM simulations how SSTs anomalies in the tropical basins can influence rainfall over NESA at interannual timescales. On the one hand, the anomalous heating in the equatorial Atlantic following an Atlantic El Niño configuration leads to increased rainfall over NESA through a southward shift of the ITCZ due to the subsidence north of the Equator. On the other, a cooling in the Pacific associated with a Pacific Niña event leads to rainfall increase over NESA through convergence in the Amazon region due to the compensation of surface divergence over the east tropical Pacific.

However, we also show that the impact of such SST interannual modes of variability on rainfall over NESA is nonstationary. While the Atlantic Niño produces rainfall variability 
at the beginning of the XX century and after 1970, the Pacific Niño does not have a big impact until the 1970s. In the period from 1920 to 1970 the rainfall variability in the NESA region could be attributed to the Atlantic interhemispheric mode. Our results also suggest that, after the 1970s, the response to concomitant anomalies of SST in the Pacific and Atlantic basins (Rodríguez-Fonseca et al., 2009) is of the same sign over NESA, producing an enhancement in the response when both basins act together.

More work is needed to identify the causes to this nonstationarity in the teleconnection between the Atlantic and the Pacific Niño with the rainfall variability. Why the Atlantic and Pacific exert a different impact on rainfall depending on the period is a question that remains open, although it could be related to the hypothesis posed in Rodríguez-Fonseca

\section{References}

Andreoli, R. V., Ferreira de Souza, R. A., Kayano, M. T., and Candido, L. A. (2012). Seasonal anomalous rainfall in the central and eastern Amazon and associated anomalous oceanic and atmospheric patterns. Int. J. Climatol. 32, 1193-1205. doi: 10.1002/joc.2345

Baines, P. G., and Folland, C. K. (2007). Evidence for a rapid global climate shift across the late 1960s. J. Climate 20, 2721-2744. doi: 10.1175/JCLI4177.1

Cazes-Boezio, G., Robertson, A. W., and Mechoso, C. R. (2003). Seasonal dependence of ENSO teleconnections over South America and relationships with precipitation in Uruguay. J. Climate 16, 1159-1176. doi: 10.1175/15200442(2003) $16<1159$ :SDOETO > 2.0.CO;2

Chiang, J. C. H., Kushnir, Y., and Zebiak, S., E (2000). Interdecadal changes in eastern Pacific ITCZ variability and its influence on the Atlantic ITCZ. Geophys. Res. Lett. 27, 3687-3690. doi: 10.1029/1999GL011268

Espinoza Villar, J. C., Ronchail, J., Guyot, J. L., Cochonneau, G., Naziano, F., Lavado, W., et al. (2009). Spatio-temporal rainfall variability in the Amazon basin countries (Brazil, Peru, Bolivia, Colombia, and Ecuador). Int. J. Climatol. 29, 1574-1594. doi: 10.1002/joc.1791

Gan, M. A., Kousky, V. E., and Ropelewski, C. F. (2004). The South America monsoon circulation and its relationship to rainfall over west-central Brazil. J. Climate 17, 47-66. doi: 10.1175/15200442(2004)017<0047:TSAMCA > 2.0.CO;2

Giannini, A., Saravanan, R., and Chang, P. (2004). The preconditioning role of tropical Atlantic variability in the development of the ENSO teleconnection: implications for the prediction of Nordeste rainfall. Clim. Dyn. 22, 839-855. doi: 10.1007/s00382-004-0420-2

Grimm, A. M., and Tedeschi, R. G. (2009). ENSO and extreme rainfall events in South America. J. Climate 22, 1589-1609. doi: 10.1175/2008JCLI2429.1

Harris, I., Jones, P. D., Osborn, T. J., and Lister, D. H. (2013). Updated high-resolution grids of monthly climatic observations-the CRU TS3. 10 Dataset. Int. J. Climatol. 34, 623-642. doi: 10.1002/joc.3711

Harzallah, A., Rocha de Aragao, J. O., and Sadourny, R. (1996). Interannual rainfall variability in North-east Brazil: observation and model simulation. Int. J. Climatol. 16, 861-878.

Hastenrath, S. (2006). Circulation and teleconnection mechanisms of Northeast Brazil droughts. Progr. Oceanogr. 70, 407-441. doi: 10.1016/j.pocean.2005.07.004

Kayano, M. T., Andreoli, R. V., and Ferreira de Souza, R. A. (2013). Relations between ENSO and the South Atlantic SST modes and their effects on the South American rainfall. Int. J. Climatol. 33, 2008-2023. doi: 10.1002/joc.3569

López-Parages, J., and Rodríguez-Fonseca, B. (2012). Multidecadal modulation of El Niño influence on the Euro-Mediterranean rainfall. Geophys. Res. Lett. 39:L02704. doi: 10.1029/2011GL050049

Losada, T., Rodríguez-Fonseca, B., Mohino, E., Bader, J., Janicot, S., and Mechoso, C. R. (2012). Tropical SST and Sahel rainfall: a non-stationary relationship. Geophys. Res. Lett. 39:L12705. doi: 10.1029/2012GL052423 et al. (2015) for the Sahel, in which changes in the ocean background state related to the Atlantic Multidecadal Oscillation are identified as possible modulators of the interannual teleconnections. Also, it is necessary to analyse the relative impact of decadal variability over the rainfall in the northeast of South America.

\section{Acknowledgments}

We are grateful to the two anonymous reviewers whose comments have helped to improve this manuscript. The research leading to these results has received funding from the European Union Seventh Framework Programme (FP7/2007-2013) under grant agreement $\mathrm{n}^{\circ} 603521$ (PREFACE project) and the Spanish project CGL2012-38923-C02-01.

Mann, M. E. (2008). Smoothing of climate time series revisited. Geophys. Res. Lett. 35:L16708. doi: 10.1029/2008gl034716

Martín-Rey, M., Polo, I., Rodríguez-Fonseca, B., and Kucharski, F. (2012). Changes in the interannual variability of the tropical Pacific as a response to an equatorial Atlantic forcing. Sci. Mar. 76, 105-116. doi: 10.3989/scimar.03610.19A

Martín-Rey, M., Rodríguez-Fonseca, B., Polo, I., and Kucharski, F. (2014). On the Atlantic-Pacific Niños connection: a multidecadal modulated mode. Clim. Dyn. 43, 3163-3178. doi: 10.1007/s00382-014-2305-3

Matsuura, K., and Willmott, C. J. (2009). Terrestrial Precipitation: 1900-2008 Gridded Monthly Time Series. Available online at: http://climate.geog.udel.edu

Mechoso, C. R., Yu, J. Y., and Arakawa, A. (2000). "A coupled GCM pilgrimage: from climate catastrophe to ENSO simulations," in General Circulation Model Development: Past, Present and Future. Proceedings of a symposium in honor of Professor Akio Arakawa, ed D. A. Randall (New York, NY: Academic), 539-575.

Moura, A. D., and Shukla, J. (1981). On the dynamics of drought in Northeast Brazil: observations, theory, and numerical experiments with a general circulation model, J. Atmos. Sci. 38, 2653-2675.

Nobre, P., and Shukla, J. (1996). Variations of sea surface temperature, wind stress, and rainfall over the tropical Atlantic and South America. J. Climate. 9, 2464-2479.

Philander, S. G. H. (1990). El Niño, La Niña, and the Southern Oscillation. Int. Geophys, 46, 293.

Polo, I., Martin-Rey, M., Rodriguez-Fonseca, B., Kucharski, F., and Mechoso, R. (2015). Processes in the Pacific La Niña onset triggered by the Atlantic Niño. Clim. Dyn. 44, 55-131. doi: 10.1007/s00382-014-2354-7

Polo, I., Rodríguez-Fonseca, B., Losada, T., and García-Serrano, J. (2008). Tropical Atlantic Variability modes (1979-2002). Part I: time-evolving SST modes related to West African rainfall. J. Climate 21, 6457-6475. doi: 10.1175/2008JCLI2607.1

Poveda, G., Waylen, P. R., and Pulwarty, R. S. (2006). Annual and interannual variability of the present climate in northern South America and southern Mesoamerica. Palaeogeogr. Palaeoclimatol. Palaeoecol. 234, 3-27. doi: 10.1016/j.palaeo.2005.10.031

Rao, V., Giarolla, B. E., Kayano, M. T., and Franchito, S. H. (2006). Is the recent increasing trend of rainfall over Northeast Brazil related sub-Saharan drought? J. Climate 19, 4448-4453. doi: 10.1175/JCLI3862.1

Rayner, N. A., Parker, D. E., Horton, E. B., Folland, C. K., Alexander, L. V., and Rowell, D. P. (2003). Global analyses of sea surface temperature, sea ice, and night marine air temperature since the nineteenth century. J. Geophys. Res. 108:4407. doi: 10.1029/2002jd002670

Richter, I., Mechoso, C. R., and Robertson., A. W. (2008). What determines the position and intensity of the South Atlantic anticyclone in Austral Winter? An AGCM study. J. Climate. 21, 214-229. doi: 10.1175/2007JCLI1802.1

Rodrigues, R. R., Reindert, J., Haarsma Campos, E. J. D., and Ambrizzi, T. (2011). The Impacts of Inter-El Niño variability on the Tropical Atlantic and Northeast Brazil climate. J. Climate 24, 3402-3422. doi: 10.1175/2011JCLI3983.1 
Rodríguez-Fonseca, B., Mohino, E., Mechoso, C. R., Caminade, C., Biasutti, M., Gaetani, M., et al. (2015). Variability and Predictability of West African Droughts: a review of the Role of Sea Surface temperature Anomalies. J. Climate 28, 4034-4060. doi: 10.1175/jcli-d-14-00130.1

Rodríguez-Fonseca, B., Polo, I., García-Serrano, J., Losada, T., Mohino, E., Mechoso, C. R., et al. (2009). Are Atlantic Niños enhancing Pacific ENSO events in recent decades? Geophys. Res. Lett. 36, 67-74. doi: 10.1029/2009GL040048

Schneider, U., Fuchs, T., Meyer-Christoffer, A., and Rudolf, B. (2008). Global Precipitation Analysis Products of the GPCC, (Offenbach: Glob.Precip. Climatol. Cent.). Available online at http://gpcc.dwd.de

Shepard, D. (1968). A two-dimensional interpolation function for irregularlyspaced data. Proc. 1968 A.C.M. Nat. Conf. 68, 517-524. doi: 10.1145/800186. 810616

Sierra, J. P., Arias, P. A., and Vieira, S. C. (2015). Precipitation over northern South America and its seasonal variability as simulated by the CMIP5 models. Adv Meteorol. 2015:634720. doi: 10.1155/2015/634720

Sperber, K. R., and Palmer, T. N. (1996). Interannual tropical rainfall variability in general circulation model simulations associated with the Atmospheric Model Intercomparison Project. J. Climate 9, 2727-2750.

Trenberth, K. E., and Stepaniak, D. P. (2001). Indices of El Niño Evolution. J. Climate. 14, 1697-1701. doi: 10.1175/1520-0442(2001)014<1697: LIOENO $>2.0 . \mathrm{CO} ; 2$
Uvo, C. B., Repelli, C. A., Zebiak, S. E., and Kushnir, Y. (1998). The relationships between tropical Pacific and Atlantic SST and Northeast Brazil monthly precipitation. J. Climate 11, 551-562.

Wilks, D. S. (2006). Statistical Methods in the Atmospheric Sciences, 2nd Edn. Amsterdam: Academic.

Willmott, C. J., Ackleson., S. G., Davis, R. E., Feddema, J. J., Klink, K. M., Legates, D. R., et al. (1985). Statistics for the evaluation and comparison of models. J. Geophys. Res. 90, 8995-8900.

Zebiak, S. E. (1993). Air-sea interaction in the Equatorial Atlantic region, J. Climate 6, 1567-1568.

Conflict of Interest Statement: The authors declare that the research was conducted in the absence of any commercial or financial relationships that could be construed as a potential conflict of interest.

Copyright $\odot 2015$ Torralba, Rodríguez-Fonseca, Mohino and Losada. This is an open-access article distributed under the terms of the Creative Commons Attribution License (CC BY). The use, distribution or reproduction in other forums is permitted, provided the original author(s) or licensor are credited and that the original publication in this journal is cited, in accordance with accepted academic practice. No use, distribution or reproduction is permitted which does not comply with these terms. 